Original paper

\title{
Long-term changes of infra-littoral zone zooxanthellate cnidarians in the Taisho Lava Field, Sakurajima, Kagoshima, Japan
}

\author{
Shusuke ONO ${ }^{1}$, James D. REIMER ${ }^{2,3, *}$, Yoko NOZAWA ${ }^{4}$, and Junzo TSUKAHARA ${ }^{5}$
}

${ }^{1}$ Miyakonojo Higashi High School, Kabayama 1996, Mimata, Miyazaki 889-1996, Japan

${ }^{2}$ Rising Star Program, Transdisciplinary Research Organization for Subtropical Island Studies, University of the Ryukyus, Senbaru 1, Nishihara, Okinawa 903-0213, Japan

${ }^{3}$ Marine Biodiversity Research Program, Institute of Biogeosciences, Japan Agency for Marine-Earth Science and Technology (JAMSTEC), 2-15 Natsushima, Yokosuka, Kanagawa 237-0061, Japan

${ }^{4}$ Biodiversity Research Center Academia Sinica 128 Academia Road Sec.2 Nankang Taipei 115 Taiwan, ROC

${ }^{5}$ Department of Developmental Biology, Faculty of Science, Kagoshima University, Korimoto 1-21-35, Kagoshima 890-0065, Japan

Corresponding author: J.D. Reimer

E-mail: reimer@sci.u-ryukyu.ac.jp

Communicated by Masayuki Hatta (Biology and Ecology Editor)

\begin{abstract}
In order to investigate long-term changes in a zooxanthellate cnidarian community in the temperatesubtropical area, we marked off a $41 \mathrm{~m}^{2}$ area at Taisho Lava Field, Sakurajima, Kagoshima, Japan. Colonies of three zooxanthellate cnidarian species (encrusting anemone Zoanthus sansibaricus Carlgren, soft coral Stereonephthya japonica Utinomi, and bubble anemone Entacmaea quadricolor sensu Fautin and Allen) in the survey area were monitored yearly in August from 1995 to 2004. Seawater temperature data were also obtained to investigate possible environmental influences on observed cnidarian changes. Sequences of internal transcribed spacer region of ribosomomal DNA (ITS-rDNA) were also obtained to identify the dinoflagellate Symbiodinium spp. endosymbionts found within each cnidarian species (subclade $\mathrm{C} 1$ / $\mathrm{C} 3$ in Z. sansibaricus and E. quadricolor, clade G in $S$. japonica). Our results show that abnormally high ocean temperatures in $1998\left(>2.0^{\circ} \mathrm{C}\right.$ than average summer sea water temperatures) were followed by significant decreases in both cover and colony number in S. japonica, which
\end{abstract}

showed no sign of recovery to the previous level. The difference in changes between the three zooxanthellate cnidarian populations may be primarily due to physiological differences at high ocean temperatures in Symbiodinium spp. hosted by the three cnidarian spp..

Keywords benthos, soft coral, zoanthid, anemone, Symbiodinium

\section{Introduction}

The phenomenon of bleaching, where Symbiodinium (zooxanthellae) are degraded and/or expelled from coral and other shallow-water zooxanthellate cnidarian hosts, resulting in drastic whitening and/or death of hosts, has been observed worldwide. Summer 1998 bleaching of zooxanthellate cnidarians associated with higher than average ocean temperatures due to a El Nino/Southern 
Oscillation (ENSO) event were well-documented worldwide (Tsuchiya 1999). In Okinawa, Japan, 1998 ENSO ocean temperatures higher than $32^{\circ} \mathrm{C}$ continued for one month, and resulting severe bleaching without historical precedent for this region was widespread (Hasegawa et al. 1999; Taniguchi et al. 1999; Kayanne et al. 1999; Fujioka 1999). While the effects of the 1998 ENSO bleaching event are well documented for zooxanthellate hard corals, comparatively little information exists on the impact of such abnormally high seawater temperatures and/or ENSO events on soft-bodied zooxanthellate cnidarians (i.e. soft corals, anemones, etc.).

Much work has been carried out on Symbiodinium spp. diversity, and it has been shown that there are eight major "clades" (of unknown taxonomic level) of Symbiodinium (Pochon et al. 2004, 2006). Within each clade are numerous subclades (e.g. see LaJeunesse 2005), and physiological differences have been demonstrated between some subclades (Tchernov et al. 2004; LaJeunesse 2005). Populations of various cnidarian species at Taisho Lava Field, Sakurajima, Kagoshima, Japan $\left(31^{\circ} 35^{\prime} \mathrm{N}, 130^{\circ} 35^{\prime} \mathrm{E}\right)$ (Fig. 1) are just north of the reef-building coral community northern boundary (approximately $30^{\circ} \mathrm{N}$ in Japan [Nishi- hira and Veron 1995]). The lava field was formed during the 1914 Taisho eruption of the Sakurajima Volcano, and is unique in its relative newness. Lava rock at the lava field consists mainly of pyroxene andosite and dacite $\mathrm{SiO}_{2}$ (57-67\% total) (Fukuyama and Ono 1981). Part of the coastline lies within a marine park (Hirata and Osako 1969), and is relatively rich in macrobenthos compared to surrounding areas. Numerous zooxanthellate hard coral (Acropora spp., Porites spp., Lithophyllon sp., Pavona decussata) and soft-bodied zooxanthellate cnidarian species (Z. sansibaricus, Z. aff. vietnamensis Pax et Muller [see Reimer et al. 2006a], S. japonica, E. quadricolor) are found in the infra-littoral zone at Sakurajima (see Ono et al. 2007 for a description of the Sakurajima site).

Here, we conducted a long-term investigation at Sakurajima on changes in sessile cnidarian macrobenthos, and also identified through genetic sequencing the strains of endosymbiotic Symbiodinium spp. found in the macrobenthos in an attempt to understand the effects of abnormally high seawater temperatures and/or ENSO.

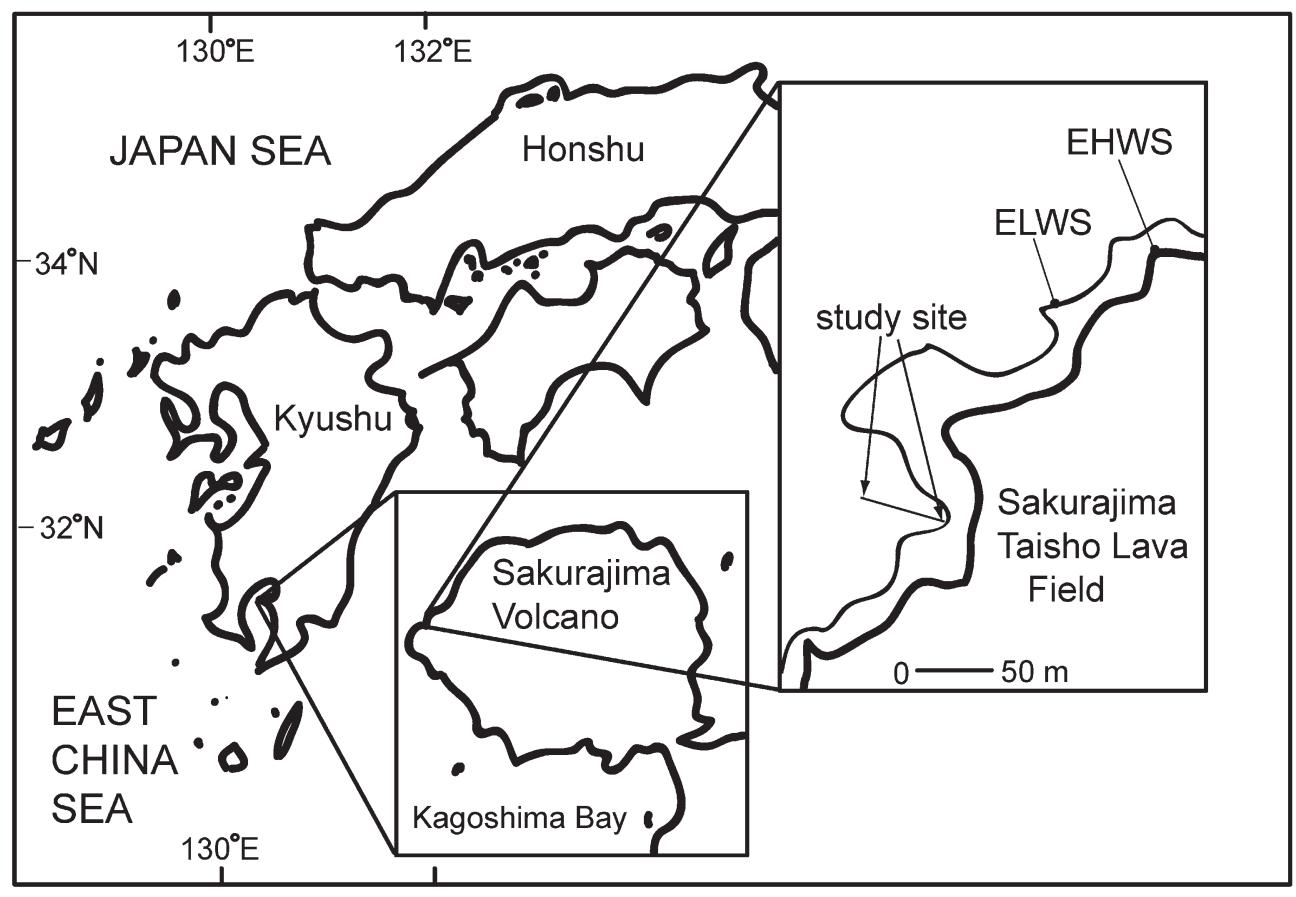

Fig. 1 Map of the study site at Taisho Lava Field, Hakamagoshi, Sakurajima, Kagoshima, Japan. ELWS = extreme low water (spring), EHWS=extreme high water (spring) 


\section{Materials and methods}

\section{Study location and monitoring survey}

The study site at the Taisho Lava Field, Hakamagoshi, Sakurajima, has been the subject of numerous previous studies by the authors and others, and has been well characterized in terms of environmental and biological data (Hirata and Osako 1969; Ono et al. 2003, 2007).

Quadrats $(1 \mathrm{~m} \times 1 \mathrm{~m}, \mathrm{n}=41)$ used in this study are the same quadrats as described in Ono et al. (2003) (Fig. 1). Originally 50 quadrats were put in place at the Taisho Lava Field, Hakamagoshi, Sakurajima, but as the site is frequented by fishermen and divers, as well as being located near a footpath along the shore, nine quadrats were found to have "unreliable" data and were removed from the data analyses. In this case "unreliable" means that benthic cnidarian data within the quadrats were seen to have undergone unexplained drastic changes (e.g. removed completely, etc.). The quadrat extends out $50 \mathrm{~m}$ into a small bay. Depth at $50 \mathrm{~m}$ from the extreme low tide shoreline is $6 \mathrm{~m}$. Survey methodology followed Ono et al. (2003). In August 1995, iron pegs were set in place every $10 \mathrm{~m}$ from the extreme low tide shoreline to a distance of $50 \mathrm{~m}$ from shore. Surveys were conducted annually by scuba diving in August for 1995-2004. Thus, high temperature influences (which potentially continue into September) were often likely not to be seen until the survey the following year. All quadrats were surveyed using a $1 \mathrm{~m} \times 1 \mathrm{~m}$ stainless steel quadrat frame with thin elastic string tied across the frame every $10 \mathrm{~cm}$. Thus, each quadrat consisted of 100 squares. Size of each macrobenthos was noted on waterproof graph paper to within 1 $\mathrm{cm}$ accuracy using Vernier calipers. All substrate was treated as a flat surface irregardless of convoluted terrain. Colony-size data were logarithmically transformed and used for size frequency distribution diagrams, which may reflect age distribution more closely than non-transformed ones in organisms with planar growth form like some coral species (Bak and Meesters 1998; Vermeji and Bak 2002).

\section{Ocean temperature and yearly thermal total (YTT) data}

Ocean temperature data (1980-2004) were obtained from the Kagoshima Prefectural Fisheries Experimental Center (KPFEC). Data were recorded every two days at several locations at a depth of $5 \mathrm{~m}$ by ferries running between Kagoshima City and Naha, Okinawa, Japan. For our study, we used data from the Taniyama Knoll location (closest to our study site) $\left(31^{\circ} 30^{\prime} \mathrm{N}, 130^{\circ} 35^{\prime} \mathrm{E}\right)$. We calculated the average "yearly thermal total" (YTT) for the period of 1981-2004 by first calculating the average weekly ocean temperature (using monthly KPFEC temperature data) for 1981-2004. Then, we subtracted this expected average ocean temperature from the observed weekly average temperature (for each month 1995-2004) and multiplied positive differences (i.e. higher than average ocean temperatures) by four (which is approximately the number of weeks per month) to calculate a "monthly thermal total". If differences were negative these were not included in YTT calculations as this method only examines warmer than average conditions. This method is very similar to the calculation of the "degree-heating week method" (DHW) utilized by the National Oceanic and Atmospheric Administration (NOAA) to reveal areas with accumulated thermal stress and potential coral bleaching areas (see Liu et al. 2003). "Monthly thermal totals" were totaled for each year (1981-2004), and an average YTT for 1981-2004 was calculated (=91.29). Then, we calculated each year's YTT for the period 19952004. We were able to compare the seawater temperature abnormality each year when compared to an average year.

\section{Identification of Symbiodinium strains}

Sequence data for the internal transcribed spacer region of ribosomal DNA ITS-rDNA) for Symbiodinium from Z. sansibaricus (Acc. Nos. AB190273-AB190276, AB 207185-AB207189 [Reimer et al. 2006c]; and DQ335255DQ355411 [Reimer et al. 2007]) and S. japonica (AB 253788, Reimer et al. 2007) were obtained in previous studies. To compare Symbiodinium in E. quadricolor to previous sequence data, small pieces of tissue were cut from sampled E. quadricolor polyps preserved at $30^{\circ} \mathrm{C}$ in $99.5 \%$ ethanol. Pieces were seen to contain innumerable 
symbiont zooxanthellae. Total DNA was extracted from these samples using a spin-column DNeasy Animal DNA Extraction kit (QIAGEN, Tokyo, Japan). PCR amplification was performed using HotStarTaq DNA polymerase (QIAGEN) according to the manufacturer's instructions. ITS-rDNA was amplified using primers ITS4 (5'-TCC TCC GCT TAT TGA TAT GC-3') (White et al. 1990) and zooxanthellae-specific zITSf (5'-CCG GTG AAT TAT TCG GAC TGA CGC AGT-3') (Rowan and Powers 1992; Hunter et al. 1997). PCR-amplified products of Symbiodinium from E. quadricolor were obtained and processed as described in Reimer et al. (2006c).

\section{Results and discussion}

During the monitoring period between 1995 and 2004, 1998 had the highest relative YTT (126.96) above the average year's (1981-2000) YTT (91.29), while 2001 (115.89) and 2004 (112.22) also had very high YTTs (Fig. 2).

Among the three zooxanthellate cnidarian species monitored (Z. sansibaricus, S. japonica, and E. quadricolor), only $S$. japonica showed a dramatic decrease in both cover and colony number after 1998 (Fig. 2). Total
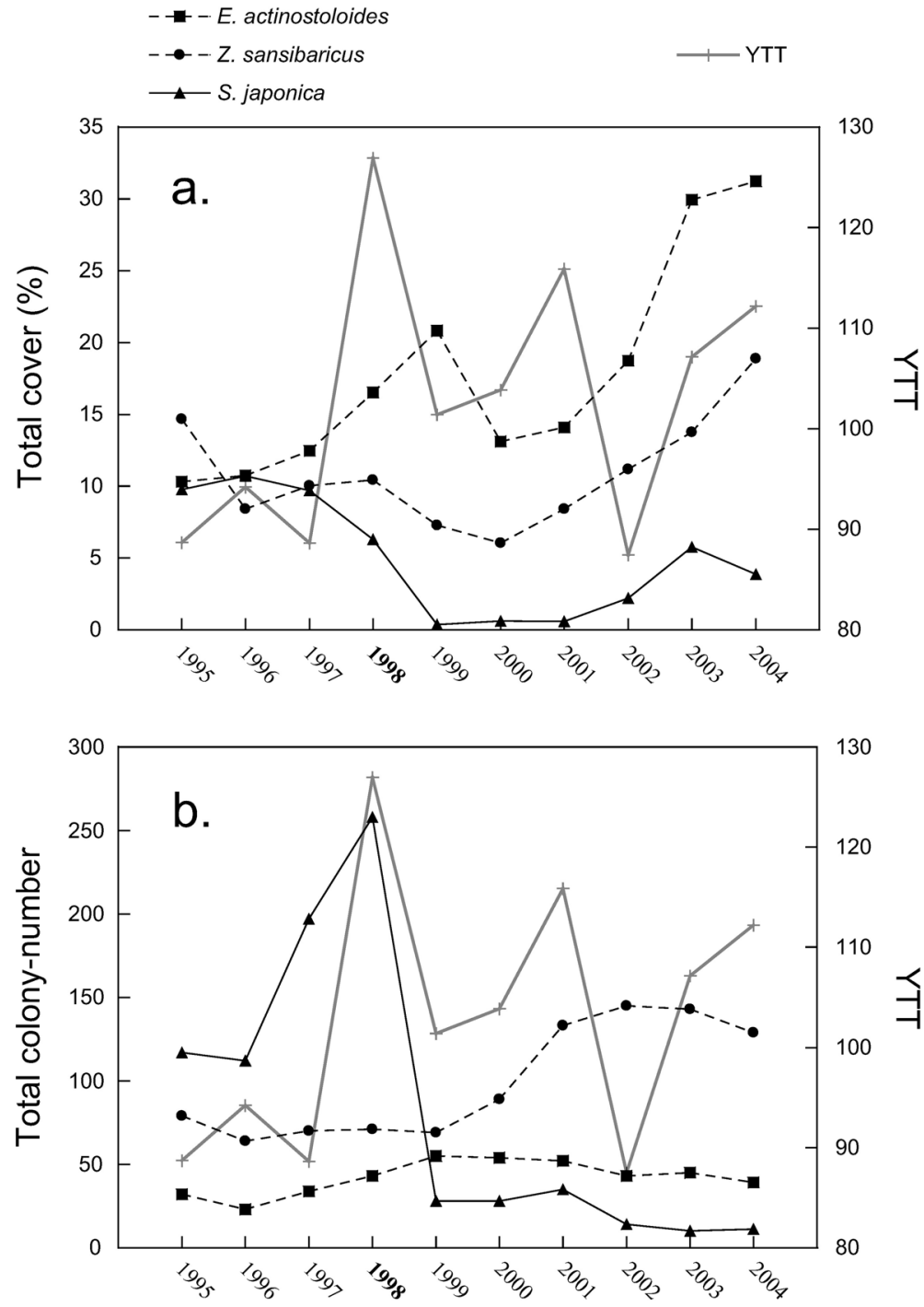

Fig. 2 Annual changes in (a) total cover and (b) total colony-number of three zooxanthellate cnidarian species in the $41 \mathrm{~m}^{2}$ area monitored from 1995 to 2004 at Sakurajima, Kagoshima, Japan. The change in yearly thermal total (YTT) (see Materials and methods) is also shown 
cover of $S$. japonica in the survey area, ranging from 6.3 to $10.7 \%$ between 1995 and 1998 , dropped rapidly to $0.4 \%$ in 1999. A small drop in S. japonica cover was observed in 1998 when compared to 1997 (Fig. 1), during the high seawater temperatures, which started in July of that year. Although slight recovery was seen from 2002 onwards, the total cover of $S$. japonica did not recover to pre-1998 levels by 2004 (3.9\%) (Fig. 2a). In colony number, the change in S. japonica before and after 1998 was more drastic (Fig. 2b). The colony number of S. japonica, ranging from 112 to 258 between 1995 and 1998, dropped drastically to 28 in 1999, and did not showed any sign of recovery by 2004 (11 colonies), six years after 1998. The size-frequency distributions of the three zooxanthellate cnidarian species showed total disappearance of $S$. japonica colonies from the middle to large size classes after 1998 whereas no obvious change was seen before and after 1998 in the other two species (Fig. 3). Furthermore, the unexpected lack of decrease observed in small S. japonica in 1998 can be explained by some residual recruitment from the few remaining $S$. japonica colonies found in deeper waters, which may have partially escaped the bleaching event of 1998 at Sakurajima. Unpublished data from plankton net experiments at the study site indicate $S$. japonica spawns July-October (Ono et al. personal observation).

$S$. japonica showed significant decreases in both cover and colony number in 1998-1999. Seawater temperatures at Sakurajima were over $30^{\circ} \mathrm{C}$ in summer 1998 for approximately four weeks, and the relative YTT for 1998 was much higher than those of other observed years. Hence, S. japonica's decrease in 1998-1999 was possibly a result of the 1998 high ocean temperature/ENSO event, and that our data suggest $S$. japonica may be more sensitive to high ocean temperatures than $Z$. sansibaricus and $E$. quadricolor. Other environmental causes of observed decreases in cnidarians asides from abnormally high ocean temperatures are unlikely, as no red tide, heavy rainfall, or ashfall (e.g. Ono et al. 2003) was observed at Sakurajima in summer 1998, and there were no large changes in abundance of other organisms (S. Ono, data not shown). After the 1998 ENSO event, S. japonica cover did not recover to pre-1998 levels. It could be possible that the 1998 ENSO event inhibited the sexual reproduction of
S. japonica in some manner. Thus, a lack of asexual reproductive tendencies ( $\mathrm{F}$. Iwase, personal communication) along with the impairment of sexual reproduction would lead to S. japonica not recovering after 1998. The long-term lack of recovery due to a lack of large numbers of new recruits arriving from other populations around the Sakurajima site suggests that $S$. japonica was possibly impacted at a larger scale than we have investigated here.

A summary of Symbiodinium ITS-rDNA region sequences in Z. sansibaricus, S. japonica, and E. quadricolor is shown in Table 1. The new Symbiodinium sequence obtained in the present study from E. quadricolor was deposited in DDBJ (Acc. No. AB259647). The PCRamplified product could be sequenced directly with minimal $(<0.5 \%)$ ambiguity (i.e. observable double peaks), indicating that the E. quadricolor sample possessed Symbiodinium of very similar genetic identity (i.e. to the subclade level, as in Rodriguez-Lanetty and Hoegh-Guldberg 2003), although the possible presence of very small amounts of other Symbiodinium clades cannot be confirmed by direct sequencing (Santos et al. 2001). The obtained full ITS-rDNA region sequence was most closely matched to two ITS-rDNA sequences (98\% base-pair matching, Acc. Nos. AY237301 [Bui et al. unpublished], AY186564 [Rodriguez-Lanetty and Hoegh-Guldberg 2003]) isolated from the corals Plesiastrea versipora and Seriotopora hystrix collected from Amami, Japan and the Great Barrier Reef, Australia, respectively. Symbiodinium subclade $\mathrm{C} 1 / \mathrm{C} 3$ are thought to be host "generalist" zooxanthellae (LaJeunesse 2005), adaptable to a variety of environmental conditions (Reimer et al. 2006b). However, ITS-rDNA sequence data from S. japonica at Sakurajima show this species is in association with Symbiodinium clade G (Table 1; Reimer et al. 2007), which has previously been found in association with soritid foraminifers in Guam (Garcia-Cuetos et al. 2005) and also Stereonephthya on the Great Barrier Reef (van Oppen et al. 2005). Although the physiology of Symbiodinium clade G has yet to be studied (X. Pochon, personal communication), the inherent physiological differences between Symbiodinium subclade $\mathrm{C} 1 / \mathrm{C} 3$ and clade $\mathrm{G}$ may account for the drastic decrease of S. japonica cover between 1998 and 1999, after the abnormally high ocean temperature event in the three zooxanthellate cnidarian species investigated in the 


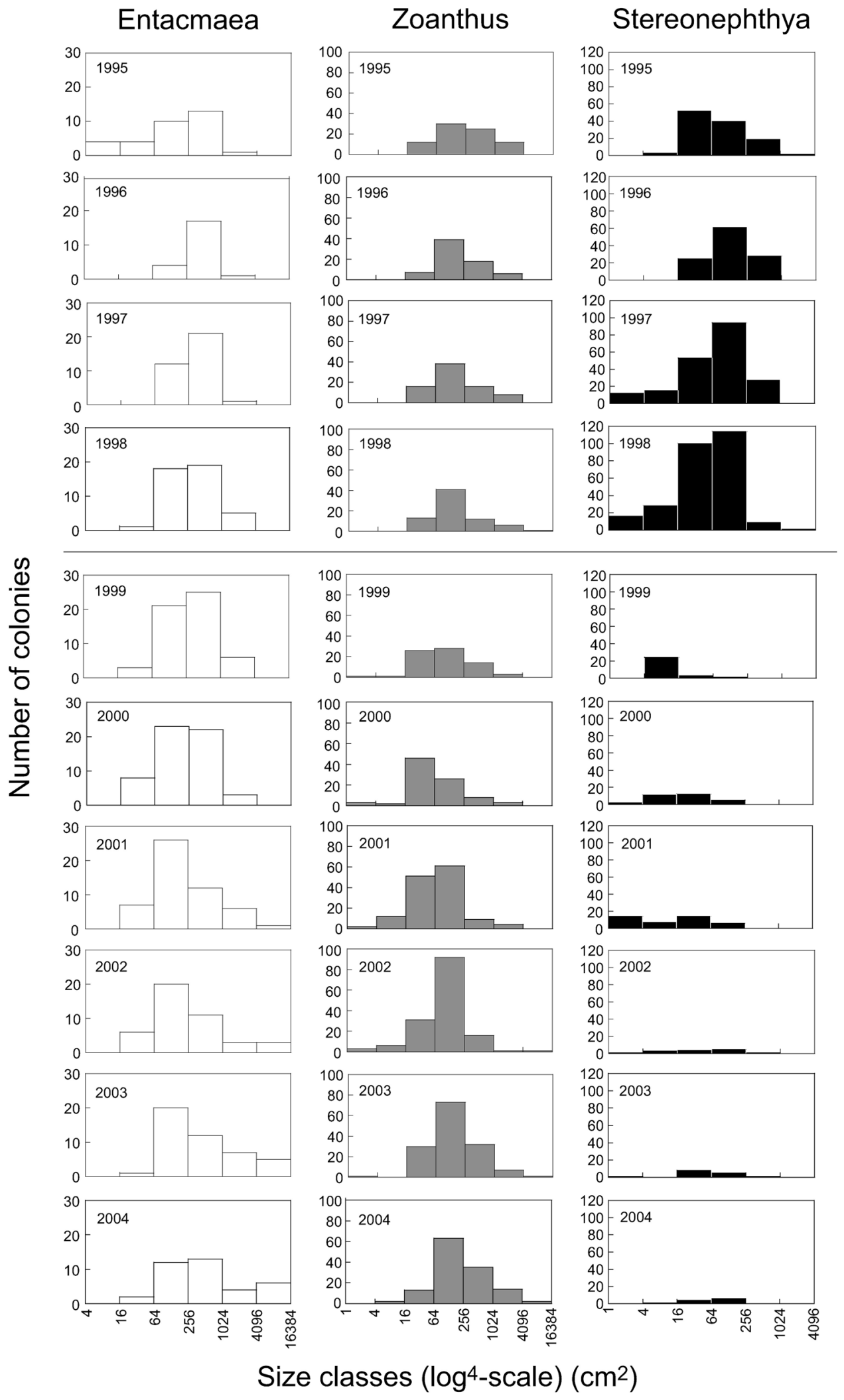

Fig. 3 Change in size-frequency distributions of three zooxanthellate cnidarians, Entacmaea quadricolor sensu Fautin and Allen, Zoanthus sansibaricus, and Stereonephthya japonica monitored from 1995 to 2004 
Table 1 Summary of Symbiodinium spp. associated with three species of clonal cnidarians at Taisho Lava Field, Sakurajima, Kagoshima, Japan

\begin{tabular}{llll}
\hline Host species & Symbiodinium type & GenBank Accession Number(s) & Reference \\
\hline Zoanthus sansibaricus & subclade C1/C3 & AB190273-AB190276 & Reimer et al. 2006d \\
& & AB207185-AB207189 & \\
\cline { 3 - 4 } & & DQ335255-DQ355411 & Reimer et al. 2006b \\
\hline Entacmaea quadricolor & subclade C1/C3 & AB259647 & this study \\
\hline Stereonephthya japonica & clade G & AB253788 & Reimer et al. 2006b \\
\hline
\end{tabular}

present study.

Our results show how different zooxanthellate cnidarians may respond to abnormally high temperatures as seen in ENSO events. With global warming of the oceans and ENSO events predicted to become more frequent in the future (Timmermann et al. 1999) these data may give us a glimpse of future community structure changes in zooxanthellate cnidarians in the warmtemperate areas.

\section{Acknowledgments}

The authors wish to thank Prof. Emeritus Yoshiko Kakinuma of the Faculty of Science, and Dr. Tadahide Noro of the Faculty of Fisheries and Aquaculture, both at Kagoshima University, for their help with the transect surveys. Fumihito Iwase (Biological Institute on Kuroshio, Otsuki, Kochi, Japan) kindly gave us information on the asexual reproductive traits of $S$. japonica, and Dr. Xavier Pochon (Hawai'i Institute of Marine Biology) provided information on Symbiodinium clade G. We extend thanks to Koji Tanaka of the Kagoshima Prefectural Fisheries Experimental Center (KPFEC) for kindly providing ocean temperature data. JDR was supported (2004-2006) by a Japan Society for the Promotion of Science (JSPS) postdoctoral fellowship (\#P04868) and the assistance of Drs. Tadashi Maruyama and Kiyotaka Takishita (JAMSTEC), as well as the Rising Star Program at the University of the Ryukyus.

\section{References}

Bak RPM, Meeeters EH (1998) Coral population structure: the hidden information of colony size-frequency distribution. Mar Ecol Prog Ser 162: 301-306

Fujioka Y (1999) Mass destruction of the hermatypic corals during a bleaching event in Ishigaki Island, southwestern Japan. Galaxea, JCRS 1: 41-50

Fukuyama H, Ono K (1981) Geological map of Sakurajima volcano. Geological Survey of Japan, Tsukuba (in Japanese)

Garcia-Cuetos L, Pochon X, Pawlowski J (2005) Molecular evidence for host-symbiont specificity in soritid foraminifera. Protist 156: 399-412

Hasegawa H, Ichikawa K, Kobayashi M, Kobayashi T, Hoshino M, Mezaki S (1999) The mass-bleaching of coral reefs in the Ishigaki lagoon, 1998. Galaxea JCRS 1: 31-39 (in Japanese with English abstract)

Hirata K, Osako Y (1969) Marine park report in Kagoshima Bay, Kagoshima, pp 9-19 (in Japanese)

Hunter, CL, Morden CW, Smith CM (1997) The utility of ITS sequences in assessing relationships among zooxanthellae and corals. Proc 8th Int Coral Reef Symp 2: 1599-1602

Kayanne H, Harii S, Yamamoto H, Tamura M, Ide Y, Akimoto F (1999) Changes in living coral coverage before and after the 1998 bleaching event on coral reef flats of Ishigaki Island, Ryukyu Islands. Galaxea, JCRS 1: 73-82 (in Japanese with English abstract)

LaJeunesse TC (2005) "Species" radiations of symbiotic dinoflagellates in the Atlantic and Indo-Pacific since the Miocene-Pliocene transition. Mol Biol Evol 22: 570-581

Liu, G, Skirving W, Strong AE (2003) Remote sensing of sea surface temperature during 2002 Barrier Reef coral bleaching. EOS 84: 137-144

Nishihira M, Veron JEN (1995) Hermatypic corals of Japan. 
Kaiyusha Publishers, Tokyo, Japan (in Japanese)

Ono S, Reimer JD, Tsukahara J (2003) Long-term changes of Zoanthus spp. in the infra-littoral zone at Taisho Lava Field, Sakurajima, Kagoshima, Japan. Galaxea, JCRS 5: 21-31

Ono S, Reimer JD, Tsukahara J (2007) Thriving cnidarian community on the volcanic coastline of Sakurajima Taisho Lava Field, southern Japan. Coral Reefs 26: 95

Pochon X, LaJeunesse TC, Pawlowski J (2004) Biogeographic partitioning and host specialization among foraminiferan dinoflagellate symbionts (Symbiodinium; Dinophyta). Mar Biol 146: 17-27

Pochon X, Montoya-Burgos JI, Stadelmann B, Pawlowski J (2006) Molecular phylogeny, evolutionary rates, and divergence timing of the symbiotic dinoflagellate genus Symbiodinium. Mol Phylogenet Evol 38: 20-30

Reimer JD, Ono S, Iwama A, Tsukahara J, Maruyama T (2006a) High levels of morphological variation despite close genetic relatedness between Zoanthus aff. vietnamensis and Zoanthus kuroshio (Anthozoa: Hexacorallia). Zool Sci 23: 755-761

Reimer JD, Ono S, Tsukahara J, Takishita K, Maruyama T (2007) Non-seasonal clade-specificity and subclade microvariation in symbiotic dinoflagellates (Symbiodinium spp.) in Zoanthus sansibaricus (Anthozoa: Hexacorallia) at Kagoshima Bay, Japan. Phycol Res 55: 58-65

Reimer JD, Takishita K, Maruyama T (2006b) Molecular identification of symbiotic dinoflagellates (Symbiodinium spp.) from Palythoa spp. (Anthozoa: Hexacorallia) in Japan. Coral Reefs 25: 521-527

Reimer JD, Takishita K, Ono S, Tsukahara J, Maruyama T (2006c) Latitudinal and intracolony ITS-rDNA sequence variation in the symbiotic dinoflagellate genus Symbiodinium (Dinophyceae) in Zoanthus sansibaricus (Anthozoa: Hexacorallia). Phycol Res 54: 122-132

Rodriguez-Lanetty M, Hoegh-Guldberg O (2003) Symbiont diversity within the scleractinian coral Plesiastrea versipora, across the northwestern Pacific. Mar Biol 143: 501509
Rowan R, Powers DA (1992) Ribosomal RNA sequences and the diversity of symbiotic dinoflagellates (zooxanthellae). Proc Natl Acad Sci USA 89: 3639-3643

Santos SR, Taylor DJ, Coffroth MA (2001) Genetic comparisons of freshly isolated versus cultured symbiotic dinoflagellates: Implications for extrapolating to the intact symbiosis. J Phycol 37: 900-912

Taniguchi H, Iwao K, Omori M (1999) Coral bleaching around Akajima, Okinawa I. A report of the 1998 survey. Galaxea, JCRS 1: 59-64 (in Japanese with English abstract)

Tchernov D, Gorbunov MY, de Vargas C, Yadav SN, Milligan AJ, Haggblom M, Falkowski PG (2004) Membrane lipids of symbiotic algae are diagnostic of sensitivity to thermal bleaching in corals. Proc Natl Acad Sci USA 101: 1353113535

Timmermann A, Oberhuber J, Bacher A, Esch M, Latif M, Roeckner E (1999) Increased El Nino frequency in a climate model forced by future greenhouse warming. Nature 398: 694-697

Tsuchiya M (1999) Warning from the coral reefs. Galaxea, JCRS 1: 27-29

Van Oppen MJ, Mieog JC, Sanchez CA, Fabricius KE (2005) Diversity of algal endosymbionts (zooxanthellae) in octocorals: the roles of geography and host relationships. Mol Ecol 14: 2403-2417

Vermeij MJA, Bak RPM (2002) Inferring demographic processes from population size structure in corals. Proc 9th Coral Reef Symp 1: 589-593

White TJ, Bruns T, Lee S, Taylor WJ (1990) Amplification and direct sequencing of fungal ribosomal genes for phylogenetics. In: Innis MA, Gelfanfd DH, Sninsky JJ, White TJ (eds) PCR protocols: A guide to methods and applications. Academic Press, San Diego, pp 315-322

Received: 22 August 2009

Accepted: 3 January 2010

C Japanese Coral Reef Society 